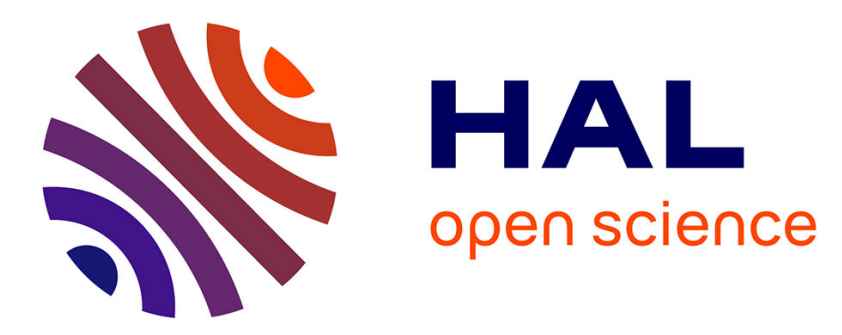

\title{
Second harmonic generation in germanotellurite bulk glass-ceramics
}

Lo Nhat Truong, Marc Dussauze, Mathieu Allix, Sébastien Chenu, Thierry Cardinal, Evelyne Fargin, Luis F. Santos

\section{- To cite this version:}

Lo Nhat Truong, Marc Dussauze, Mathieu Allix, Sébastien Chenu, Thierry Cardinal, et al.. Second harmonic generation in germanotellurite bulk glass-ceramics. Journal of the American Ceramic Society, 2017, 100 (4), pp.1412-1423. 10.1111/jace.14745 . hal-01528796

\section{HAL Id: hal-01528796 \\ https://hal.science/hal-01528796}

Submitted on 31 May 2017

HAL is a multi-disciplinary open access archive for the deposit and dissemination of scientific research documents, whether they are published or not. The documents may come from teaching and research institutions in France or abroad, or from public or private research centers.
L'archive ouverte pluridisciplinaire HAL, est destinée au dépôt et à la diffusion de documents scientifiques de niveau recherche, publiés ou non, émanant des établissements d'enseignement et de recherche français ou étrangers, des laboratoires publics ou privés. 


\title{
Second harmonic generation in germanotellurite bulk glass-ceramics
}

\author{
Lo Nhat Truong ${ }^{1,2,3,4}$ Marc Dussauze ${ }^{3}$ Mathieu Allix ${ }^{5}$ Sébastien Chenu ${ }^{1}$ Thierry Cardinal ${ }^{2}$ Evelyne Fargin ${ }^{2}$ Luis F. Santos \\ 4 \\ 1 - Faculty of Applied Sciences, Ton Duc, Thang University, Ho Chi Minh city, Vietnam \\ 2 - CNRS, Université de Bordeaux, ICMCB, Pessac, France \\ 3 - Institut des Sciences Moléculaires-UMR, 5255 CNRS, Université Bordeaux, Talence, France \\ 4 - Centro de Quimica Estrutural, Instituto Superior T_ecnico, Universidade de Lisboa, Lisboa, Portugal \\ 5 - CNRS, CEMHTI UPR3079, University of Orléeans, Orléans, France
}

\section{Abstract}

In this study, we have investigated the use of silver cation as nucleating agent in germanotellurite glass matrix of compositions $(100-x)$ [70 $\left.7 \mathrm{TeO}_{2}-10 \mathrm{GeO}_{2}-10 \mathrm{Nb}_{2} \mathrm{O}_{5}-10 \mathrm{~K}_{2} \mathrm{O}\right]-x \mathrm{Ag}_{2} \mathrm{O}(x=0-6 \mathrm{~mol} \%)$, in order to promote bulk crystallization. Density measurements, differential scanning calorimetry, X-ray diffraction, UV-Vis, and Raman spectroscopies have been performed to study the crystallization process. We have observed bulk crystallization of a unique noncentrosymmetric phase, $\mathrm{K}\left[\mathrm{Nb}_{1 / 3} \mathrm{Te}_{2 / 3}\right]_{2} \mathrm{O}_{4.8}$, which has been investigated for its second-order optical activity. Transparent to translucent glass-ceramics have been successfully tailored under thermal treatment and second harmonic generation signals were recorded on the glass-ceramic samples as a function of their synthesis procedure. It is suggested that the second-order optical properties observed are strongly related to the organization of crystallites within phase-separated domains.

\section{Introduction}

For the last two decades, optical nonlinearity, especially second-order nonlinearity (SON), has become a key property for many applications in the domain of photonics, notably for electro-optical effects and frequency conversion. Noncentrosymmetric crystals are well-known materials for these applications. However, they are complex to manufacture and their optical properties are strongly dependant on crystal orientation. One way to circumvent this problem is to replace the single crystals with new materials like glass-ceramics which can present a favorable combination of ferroelectric crystals and glass matrix where SON does not exist due to centrosymmetric organization.[1, 2] Several glass-ceramic materials presenting second harmonic generation (SHG) arising from $\mathrm{LaBGeO}_{5}, \mathrm{LiNbO}_{3}, \mathrm{and}$ $\mathrm{KNbO}_{3}$ crystals have been reported[3-5] but their low transparency still limits commercial applications.

Optical glass-ceramics require high transparency and high SON.[2,6] To ensure the quality of the transmission in glassceramics, two common solutions are envisaged: size restriction of crystals and/or reduction of the refractive index difference between the glass and the crystallized parts.[7-9] The latter requirement can be fulfilled by a careful choice of glass matrix and crystal phase, while the former requires controlled heat treatment conditions. Regarding the host-glass compositions, tellurite compositions remain one of the most promising glass formers because of their low melting temperature and the fact that the refractive indices of those glasses and many ferroelectric crystals are quite similar.[10] This means that low scattering losses at the interface between glass and crystals can be obtained and therefore high transparency might be achieved. Another possibility is to control the time and temperature of annealing to obtain small crystals of sub-micron size and thus reduce the scattering of light.[2] However, in order to control the crystal growth in the bulk, it is necessary to avoid dominant surface crystallization and promote bulk crystallization.[11, 12] Only few reported works show elaboration and optical properties characterizations of transparent tellurite glass- 
ceramics containing a high crystal volume fraction. $[2,13]$ This can be attributed to preferential surface crystallization in tellurite-based glasses.[2, 12]

Monteiro et al. have studied the $\mathrm{TeO}_{2}-\mathrm{GeO}_{2}-\mathrm{Nb}_{2} \mathrm{O}_{5}-\mathrm{K}_{2} \mathrm{O}$ germanotellurite system, $[14,15]$ where the combination of the $\mathrm{TeO}_{2}$ and $\mathrm{GeO}_{2}$ glass-forming constituents results in highly stable glasses, especially for high germanate and high tellurite compositions. The high tellurite content compositions presented higher refractive index and among these, the $70 \mathrm{TeO}_{2}-10 \mathrm{GeO}_{2}-10 \mathrm{Nb}_{2} \mathrm{O}_{5}-10 \mathrm{~K}_{2} \mathrm{O}$ composition presented the highest stability with a $T_{x}-T_{\mathrm{g}}$ difference of $\sim 137^{\circ} \mathrm{C}[14]\left(T_{x}\right.$ is the onset crystallization temperature and $T_{\mathrm{g}}$ is the glass transition temperature) and was chosen for further studies. On the other hand, the major crystalline phase obtained $\left(\mathrm{K}\left[\mathrm{Nb}_{1 / 3} \cdot \mathrm{Te}_{2 / 3}\right]_{2} \mathrm{O}_{4.8}\right)$ is known to present second harmonic generation properties. However, crystallization studies revealed that these compositions present strong surface crystallization; therefore, we have added a silver compound, in order to promote bulk crystallization and to obtain homogeneous glass-ceramics with second order optical properties. Silver introduction in the glass composition is a wellknown method of promoting crystallization and usually, 0.5 to $1 \mathrm{~mol} \% \mathrm{Ag}_{2} \mathrm{O}$ have a strong effect on the crystallization rate.[16, 17] However, in this work, doping levels of 0.5 to $1 \mathrm{~mol} \%$ did not present a striking effect on crystallization and higher amounts of silver nitrate were tested.

\section{Experimental Procedure}

Germanotellurite glasses with compositions $(100-x)\left[70 \mathrm{TeO}_{2}-10 \mathrm{GeO}_{2}-10 \mathrm{Nb}_{2} \mathrm{O}_{5}-10 \mathrm{~K}_{2} \mathrm{O}\right]-x \mathrm{Ag}_{2} \mathrm{O}(\mathrm{mol} \%)$ for $x=0,2,4,6$ mol\% (labeled 7T1G, 7T1G2Ag, 7T1G4Ag, and 7T1G6Ag, respectively) were prepared by traditional melt-quenching method. Silver was introduced as silver nitrate $\left(\mathrm{AgNO}_{3}, 99.995 \%\right.$, Alfa Aesar, Karlsruhe, Germany) and the $\sim 8 \mathrm{~g}$ batches were melted in platinum crucibles at $900^{\circ} \mathrm{C}$ for 30 minutes and annealed at $300^{\circ} \mathrm{C}$ for 6 hours. Further details are presented elsewhere.[14]

Density of the glasses was measured using the Archimedes principle by calculating the difference of a sample mass measured in air and then immersed in toluene, $\rho=0.870 \mathrm{~g} / \mathrm{cm}^{3}$.

Differential Scanning Calorimetry (DSC) was performed to determine their thermal characteristics, namely the glass transition temperature $T_{\mathrm{g}}$ and the onset crystallization temperature $T_{x}$. Glass samples were crushed into small pieces (1$2 \mathrm{~mm}$ ) or grinded into fine powders $(\sim 80 \mu \mathrm{m})$ to analyze the behavior of surface and bulk crystallization, which is related to the surface area. The sample weight ranged from $30-40 \mathrm{mg}$. The heating rate was $20^{\circ} \mathrm{C} / \mathrm{min}$. The accuracy is $\pm 2^{\circ} \mathrm{C}$. Thermal characteristics and density are summarized in Table 1.

TA B LE 1 Thermal characteristics, refractive index, and density of the silver oxide-doped germanotellurite glasses

\begin{tabular}{|c|c|c|c|c|c|c|c|c|}
\hline \multirow[b]{2}{*}{ Sample } & \multirow[b]{2}{*}{$\boldsymbol{T}_{\mathrm{g}}\left({ }^{\circ} \mathrm{C}\right)( \pm \mathbf{2})$} & \multicolumn{2}{|c|}{$\boldsymbol{T}_{x 1}\left({ }^{\circ} \mathrm{C}\right)( \pm 2)$} & \multicolumn{2}{|c|}{$\boldsymbol{T}_{x 2}\left({ }^{\circ} \mathrm{C}\right)( \pm 2)$} & \multirow{2}{*}{$\begin{array}{l}n(\text { at } 532 \mathrm{~nm}) \\
( \pm 0.005)\end{array}$} & \multirow{2}{*}{$\begin{array}{l}\rho\left(\mathrm{g} / \mathrm{cm}^{3}\right) \\
( \pm 0.005)\end{array}$} & \multirow{2}{*}{$\begin{array}{l}\text { Thickness (mm) } \\
( \pm 0.005)\end{array}$} \\
\hline & & Powder & Bulk & Powder & Bulk & & & \\
\hline 7T1G & 377 & 459 & 478 & - & - & 2.021 & 4.858 & 0.903 \\
\hline 7T1G2Ag & 360 & 436 & 455 & - & - & 2.039 & 4.896 & 0.991 \\
\hline 7T1G4Ag & 351 & 429 & 434 & 470 & - & 2.036 & 5.026 & 1.042 \\
\hline 7T1G6Ag & 339 & 417 & 420 & 540 & 541 & 2.043 & 5.063 & 0.924 \\
\hline
\end{tabular}

Glass-ceramics were elaborated, from the 7T1G6Ag-based glass, using two different heat treatment methods: a 1-step heat treatment, performed at a single temperature and a two-step heat treatment with a nucleation step and a crystal growth step. For the one-step heat treatment, various heat treatment temperatures and durations were tested and $440^{\circ} \mathrm{C}\left(>T_{x 1}\right.$, see Table 1 ) was the temperature chosen since lower or higher temperatures required either too long or too short heat treatment times, respectively, before crystallization was achieved. Similarly, for the two-step heat 
treatment, the crystal growth temperature chosen for this composition was $400^{\circ} \mathrm{C}$, while the nucleation temperature for the 7T1G6Ag glass composition was determined (Figure 1) as $340^{\circ} \mathrm{C}$ by the Marotta's method.[18]

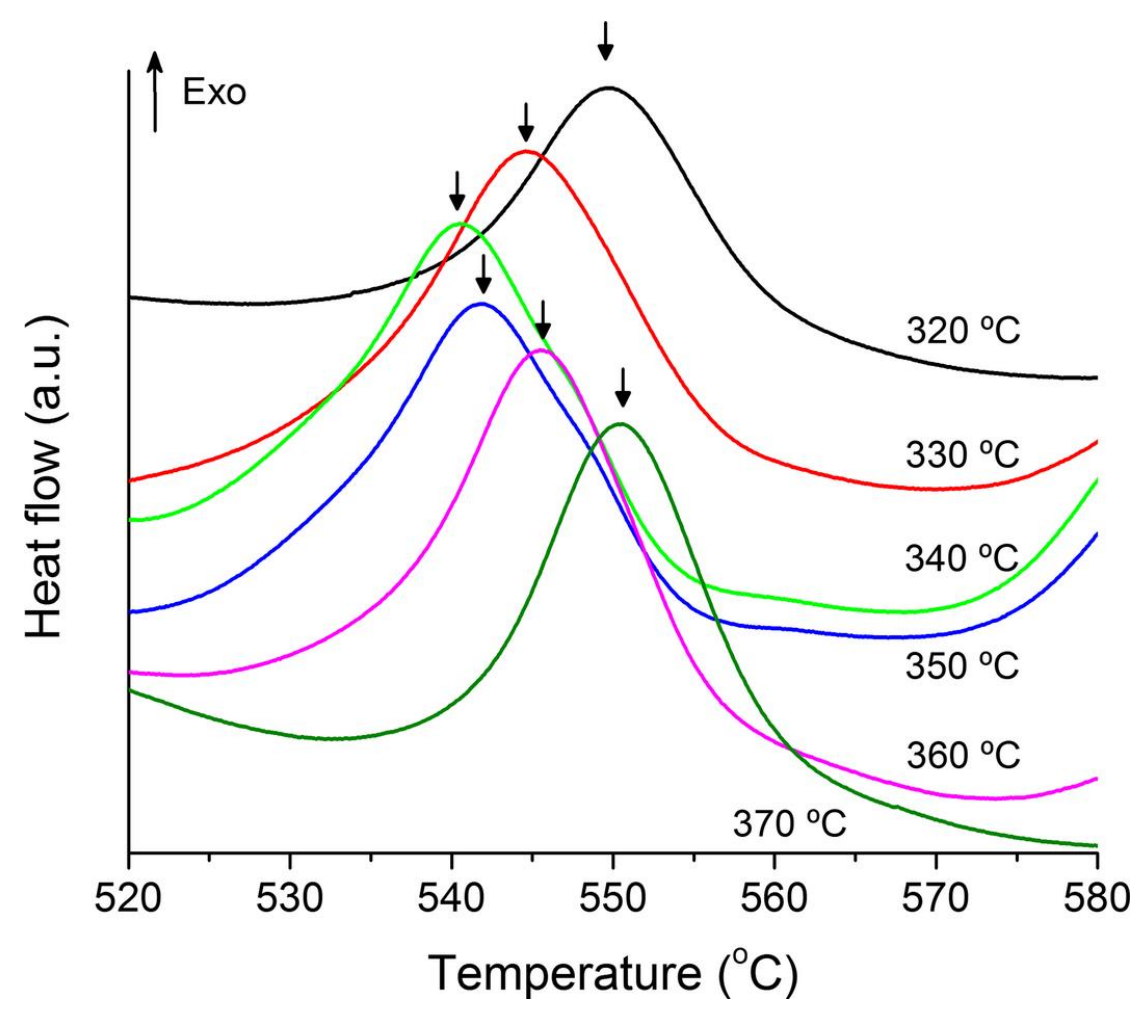

Figure 1. - Crystallization peak obtained for a $15 \mathrm{~min}$ thermal hold at different nucleation temperatures of the 7T1G6Ag glass sample.

The two most representative series of glass-ceramic samples obtained from the 7T1G6Ag glass composition are labeled: (i) $1 \mathrm{~S} 05,1 \mathrm{~S} 15$, and $1 \mathrm{~S} 30$ prepared by a one-step heat treatment at $440^{\circ} \mathrm{C}$ during $5,15,30$, and 45 minutes, respectively, and (ii) samples $2 \mathrm{~S} 15$ and $2 \mathrm{~S} 30$ based on two-step treatment consisting of a first step at $340^{\circ} \mathrm{C}$ during 3 hours to promote the nucleation, followed by a growth step, at $400^{\circ} \mathrm{C}$, during 15 minutes and 30 minutes, respectively. All glassceramic samples were finally polished again on both sides to remove possible surface crystallization (Figure 2). A highly crystallized sample-2S8 h ( 3 hours at $340^{\circ} \mathrm{C}$ for nucleation and 8 hours at $400^{\circ} \mathrm{C}$ for crystal growth) was also prepared. 


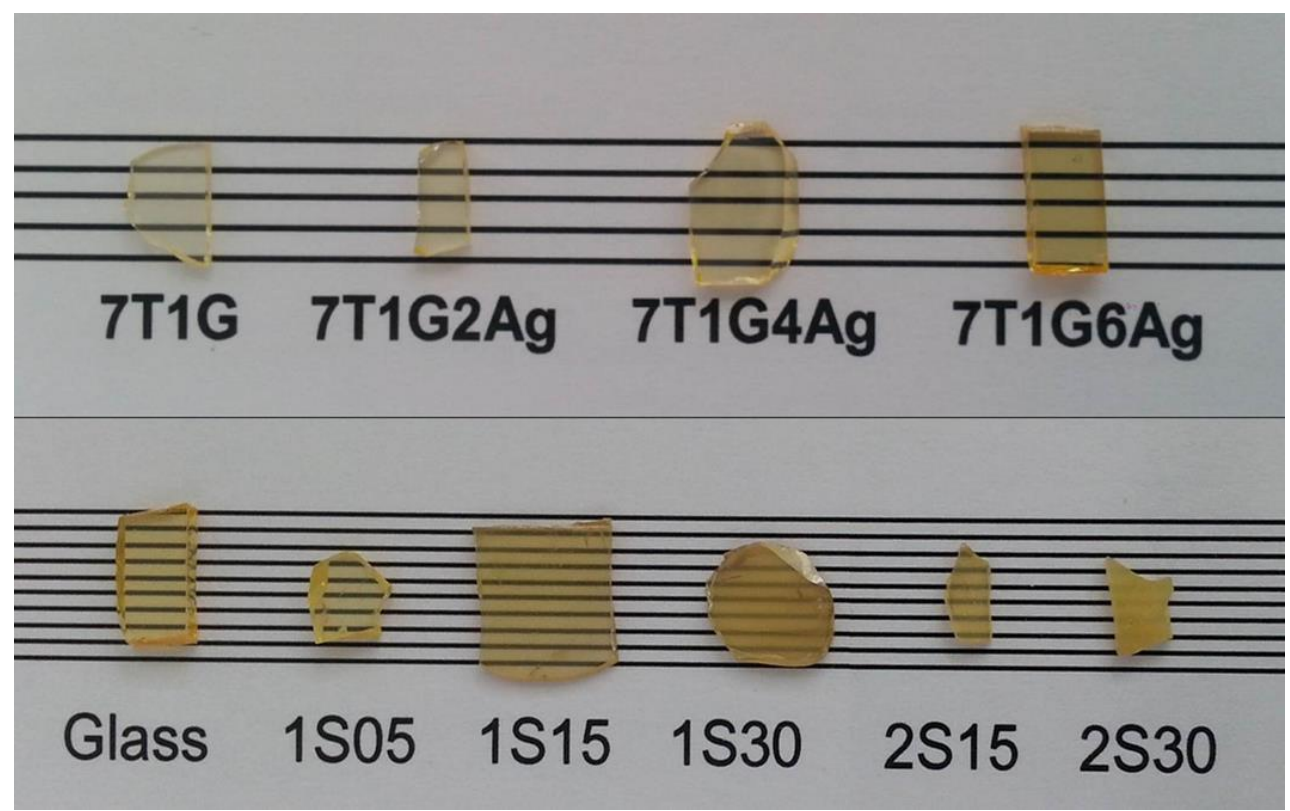

Figure 2. - 7T1GXAg glasses ( $\mathrm{x}=0$, 2, 4, and 6; top) and glass-ceramic (bottom) samples based on 7T1G6Ag with different heat treatments.

Optical transmittance spectra (UV-Vis) were recorded on optically polished $1 \mathrm{~mm}$-thick samples at room temperature using a double-beam spectrophotometer CARY (UV-Vis-NIR) in the wavelength range $200-800 \mathrm{~nm}$. Local structure analysis of glasses was accomplished by Raman spectroscopy. The Raman system, a LabRAM HR 800 Evolution from HORIBA Jobin Yvon SAS (Villeneuve d'Ascq, France), consists of a diode laser (Ventus) working at $532 \mathrm{~nm}$ and a Peltiercooled $\left(-70^{\circ}\right)$ Horiba Symphony II CCD detector with $1024 \times 256$ pixels. The Raman spectra of those glasses with different amount of silver oxide were collected from 300 to $1000 \mathrm{~cm}^{-1}$. Crystalline phase characterization was obtained from X-ray diffraction (XRD). The XRD was performed using a Phillips Panalytical (Almelo, the Netherlands) X'Pert X-ray diffractometer to analyze the crystalline phases of the heat-treated glass samples, using $\mathrm{Cu} K_{\alpha}$ radiation at room temperature. The step angle was fixed to $0.017^{\circ}$ with a time per step of 59 seconds for a standard scan and 699 seconds for a long acquisition scan. Instrumental broadening was determined by using a NIST standard (Si powder with $1 \mu \mathrm{m}$ diameter) and was taken into account in the results. Ceramized areas were observed on a Leica (Wetzlar, Germany) DMI3000M optical microscope using a 50x magnification. Transmission electron microscopy (TEM) data were collected on a Philips CM20 microscope fitted with an Oxford energy dispersive spectrometry (EDS) analyzer. To avoid any evolution of the sample under the electron beam, the experiments were performed at $80 \mathrm{keV}$.

Macroscopic SHG measurements were done in the transmission mode. The measurements consist of continuous polarization scans of the input beam at a fixed incidence angle. The incident beam, initially polarized out of the plane of incidence, is passed through a combination of a rotating half wave plate $(\Psi / 2)$ and a fixed quarter wave plate (vertical fast axis) to address all possible polarizations, from linear to elliptical and to circular polarization. The incident beam is focused on the sample with a spot size of $100 \mu \mathrm{m}$ and the transmitted second harmonic light is resolved into the parallel $(p)$ and perpendicular $(s)$ to the horizontal plane of incidence, polarized components. These analyses were performed using a Spectra Physics Nd:YAG laser 1064 nm, 20 Hz, 20 ns pulses with a typical energy of $250 \mu$ J. More details can be found elsewhere. $[6,19]$

The set-up for micro-SHG measurement is a modified micro-Raman (HR 800, HORIBA Jobin Yvon SAS) instrument equipped with a picosecond laser at $1064 \mathrm{~nm}$ for SHG measurement. The confocal microscope and motorized stages (X, $\mathrm{Y}, \mathrm{Z}$ ) allow SHG measurements in the bulk of the samples.[6] 


\section{Results}

\subsection{Glass samples}

Characteristic temperatures $\left(T_{\mathrm{g}}, T_{x 1}\right.$ and $\left.T_{x 2}\right)$ of all glasses are listed in Table 1 and DSC curves of glasses heated at 20 $\mathrm{K} / \mathrm{min}$ are shown in Figure 3. Glass transition temperature decreases from $377^{\circ} \mathrm{C}$ to $339^{\circ} \mathrm{C}$ with the progressive insertion of silver oxide. Besides that, a second crystallization peak appears with increasing silver oxide addition and the gap between $T_{x 1}$ and $T_{x 2}$ rises when the silver oxide content increases. Comparing bulk and powder analysis, it can be observed that the crystallization peak increases in intensity for the powder samples, i.e., with lower particle size as observed in Figure 3A-C. According to Marotta et al.,[18] this might be due to preferential surface crystallization with the increase in the peak intensity being due to the increase number of nucleation sites with increasing surface area. On the other hand, the peak intensities of Figure 3D (7T1G6Ag composition), remain the same for bulk and powder forms, thus indicating both superficial and bulk crystallization (see $T_{x}$ comparisons in Table 1).
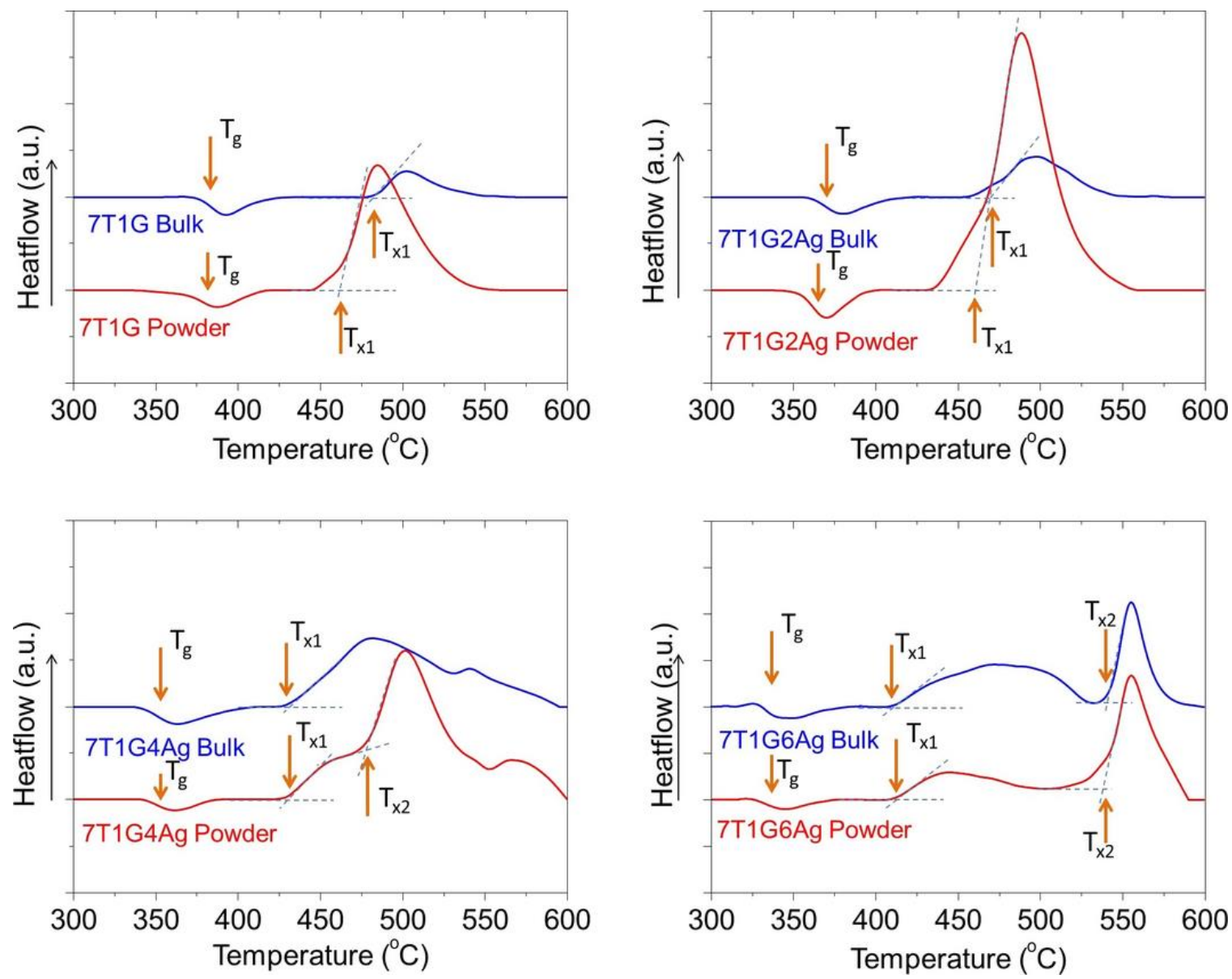

Figure 3. - DSC curves of 7T1GXAg ( $x=0,2,4$, and 6) glasses. Red and blue curves correspond to powder and bulk scans, respectively. $\mathrm{T}_{g}$ and $\mathrm{T}_{\mathrm{x}}$ are indicated in the onset of each peak.

To investigate the crystal phases precipitating in each glass composition, heat treatments were performed near the onset of the different crystallization peaks for each composition. The glasses were crushed, heated during 12 hour and characterized by XRD diffraction. As observed in Figure 4, the main crystalline phase appearing in the 7T1G composition is $\delta-\mathrm{TeO}_{2}$. With increasing $\mathrm{Ag}_{2} \mathrm{O}$ content, this phase reduces in preponderance and other phases rise, such as the crystalline phase $\mathrm{K}\left[\mathrm{Nb}_{1 / 3} \mathrm{Te}_{2 / 3}\right]_{2} \mathrm{O}_{4.8}$. In fact, for 6 mol\% $\mathrm{Ag}_{2} \mathrm{O}$ addition, heat treatment at $400^{\circ} \mathrm{C}\left(\sim T_{x 1}\right)$ evidences the crystallization of only this phase (Figure 4), while for the heat treatment at $550^{\circ} \mathrm{C}\left(\sim T_{x 2}\right)$ other phases appear, one of them could be assigned to $\mathrm{Y}-\mathrm{TeO}_{2}$. 


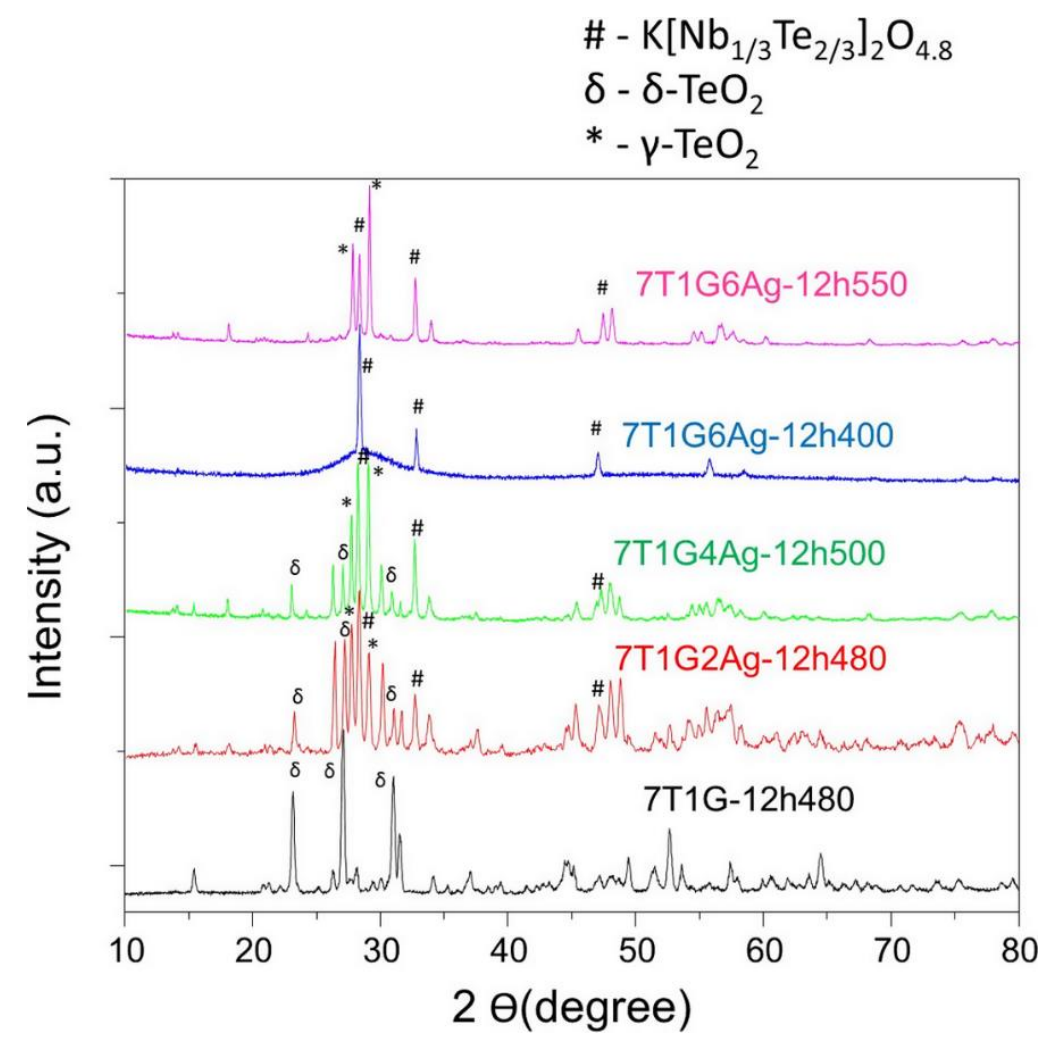

Figure 4. - XRD patterns of heat-treated7T1GXAg compositions. The heat treatment temperature was chosen, for each composition, to meet the condition $\left(\mathrm{T}>\mathrm{T}_{\mathrm{x} 1}\right)$. In the figure, \# is $K\left[\mathrm{Nb}_{1 / 3} \mathrm{Te}_{2 / 3}\right]_{2} \mathrm{O}_{4.8}, \delta$ is $\delta$-TeO $\mathrm{O}_{2}$ and ${ }^{*} \mathrm{\gamma}-\mathrm{TeO} \mathrm{O}_{2}$.

To illustrate the structural modification of glass samples in respect to silver oxide content, normalized Raman spectra of all glass samples are presented in Figure 5. All spectra exhibit two broad intense features which are similar to previous studies of tellurite glasses.[14, 20-23] The region at $400-550 \mathrm{~cm}^{-1}$ has been attributed to the bending vibrations of the Te-O-Te linkages, while the high-frequency region, which consists of a broad peak at $650-670 \mathrm{~cm}^{-1}$ and two shoulders at $720-750 \mathrm{~cm}^{-1}$ and $850-900 \mathrm{~cm}^{-1}$, is ascribed to the stretching mode of the $\mathrm{TeO}_{4}$ trigonal bipyramid (tbp) and TeO ${ }_{3+1}$ or $\mathrm{TeO}_{3}$ trigonal pyramid (tp), respectively, whereas the last one belongs to the stretching mode of $\mathrm{Nb}-\mathrm{O}$ bonds. [14, 24]

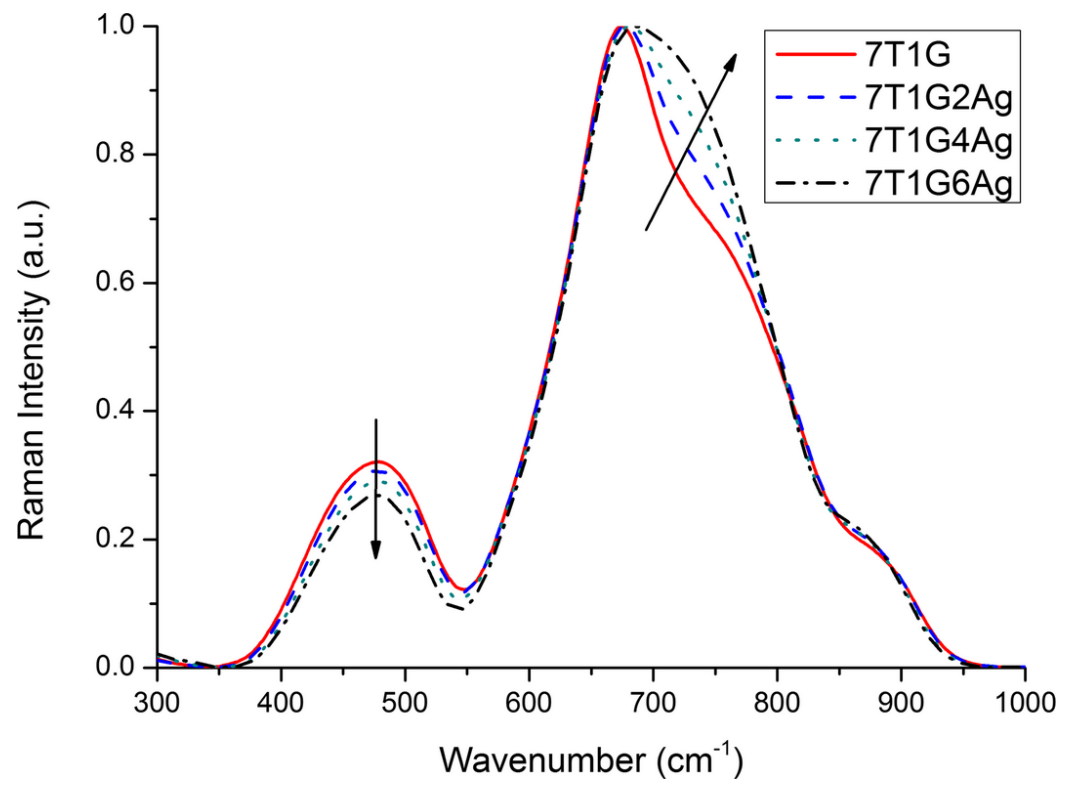

Figure 5. - Normalized Raman spectra of germanotellurite glasses with different amounts of silver oxide. 
Raman spectra of germanotellurite glasses with $10 \mathrm{~mol}^{2}$ of $\mathrm{GeO}_{2}$ mainly present specific features of tellurite-based glasses, in which the glass network is built of $\mathrm{TeO}_{4}$ tbp and $\mathrm{TeO}_{3+1} / \mathrm{TeO}_{3}$ tp entities.[25-27] In such $\mathrm{TeO}_{2}$-rich glasses, the vibration bands attributed to $\mathrm{GeO}_{x}$ entities could be overlapped by strong bands of $\mathrm{TeO}_{x}$ entities, though $\mathrm{Ge}-\mathrm{O}-\mathrm{X}$ ( $\mathrm{X}=\mathrm{Te}$, Ge) bridging bond vibration cannot be excluded in the region $400-550 \mathrm{~cm}^{-1}$ as a maximum is observed at $420 \mathrm{~cm}^{-1}$ in the $\mathrm{GeO}_{2}$ glass spectrum attributed to Ge-O-Ge symmetric stretching vibration.[14] By adding silver oxide, an intensity increase of the shoulder (at $770 \mathrm{~cm}^{-1}$ ), attributed to $\mathrm{TeO}_{3+1} / \mathrm{TeO}_{3}$ tp vibrations, is observed. This indicates that the interaction of $\mathrm{Ag}$ ions with the network leads to the disruption of $\mathrm{TeO}_{4}$ tbp units and their conversion to $\mathrm{TeO}_{3+1} / \mathrm{TeO}_{3}$ tp units. This effect is also consistent with previous studies. [25, 28]

The transmittance spectra in the Ultra Violet-Visible (UV-Vis) region are presented in Figure 6A for all glass compositions. As other tellurite-based glasses, germanotellurite glasses also have high refractive indices[14] which lead to high reflection losses around $20 \%$ (estimated by the Fresnel formula), which is close to the experimental results observed in Figure 6A.
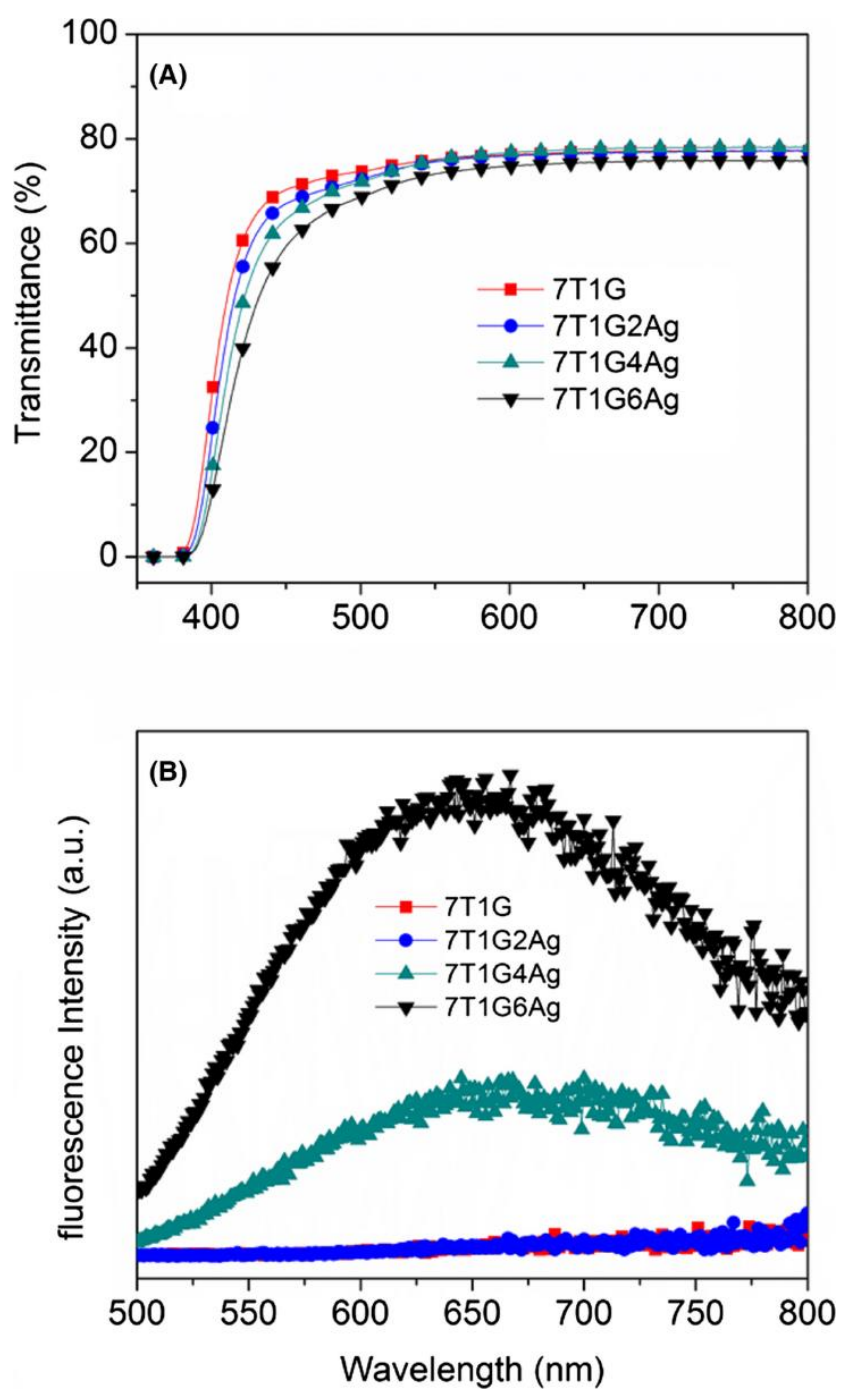

Figure 6. - (A) Transmittance curves and (B) emission spectra (excitation @485 nm) of all glass samples with compositions $(100-\mathrm{x})\left[70 \mathrm{TeO}_{2}-10 \mathrm{GeO}_{2}-10 \mathrm{~K}_{2} \mathrm{O}-10 \mathrm{Nb}_{2} \mathrm{O}_{5}\right]-\mathrm{xAg}_{2} \mathrm{O}$, where $\mathrm{x}=0-6 \mathrm{~mol} \%$.

The cut-off on the UV side is observed at around $400 \mathrm{~nm}$ and all glasses present a light yellowish color. The cut-off shows a red-shift with respect to the pristine glass as a sequence of silver oxide incorporation. The formation of silver clusters observed previously in literature[29,30] could also be at the origin of the band-gap reduction. To further investigate the origin of such additional absorption, a photoluminescence (PL) experiment was carried out for the glasses under investigation. The PL experiments were performed by using a $485 \mathrm{~nm}$ laser excitation which is at the 
wavelength cut-off of the transmission window of 7T1GxAg glass samples and the emission signals were detected in the range $500-800 \mathrm{~nm}$ (Figure 6 B). A broad band can be observed between 500 and $800 \mathrm{~nm}$, with maximum at $\sim 650 \mathrm{~nm}$ only for the silver rich glasses 7T1G4Ag and 7T1G6Ag. By comparing these results to previous studies reported on silver iondoped soda-lime silicate glasses[31-33] or phosphate glasses containing large concentrations of silver ions,[34] one may expect an emission band observed between 300 and $450 \mathrm{~nm}$ for excitation at $280 \mathrm{~nm}$ attributed to isolated $\mathrm{Ag}^{+}$ions and an additional broad band in the $450-800 \mathrm{~nm}$ range for excitation at $350 \mathrm{~nm}$ attributed to the formation of $\mathrm{Ag}^{+}-\mathrm{Ag}^{+}$ dimers or small silver ions clusters. Considering our case, where excitation below $480 \mathrm{~nm}$ cannot be performed because of the cut-off wavelength of the glass matrix, one can only suggest that the presence of silver ions clusters increases for the higher content of $\mathrm{Ag}_{2} \mathrm{O}$ (4-6\%).

Transmission electron microscopy observations of the glass samples reveal the presence of circular-shape droplets on the scale of 2-5 nm, indicating the existence of nanoscopic phase separation in the glass of 7T1G6Ag and 7T1G compositions (Figure $\underline{7} A, B$ ). This phase separation was also observed for fast quenching in which the crucible with the melt was put directly in cold water.

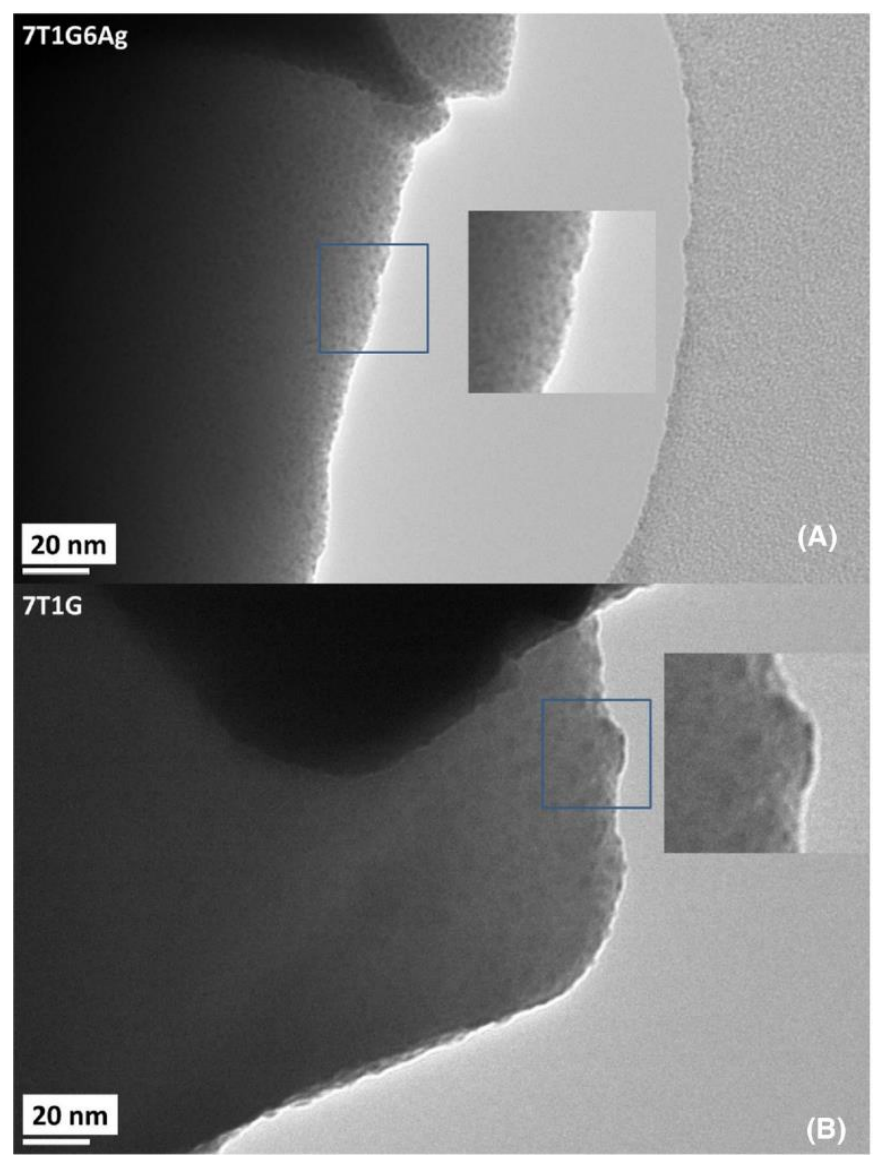

Figure 7. - Transmission electron microscopy image of (A) 7T1G6Ag and (B) 7T1G glasses showing phase separation.

\subsection{Glass-ceramic samples}

Heat treatment of glass samples has yielded different results, depending on the heat treatment procedure, as observed in Figure 8 for the 1S15, 1S30, 2S15, and 2S30 samples, where different microscopic size domains can be observed. For the one-step heat treated samples, they have the shape of 6-pointed (inset of Figure 8) or 8-pointed star-like polygons and their size increases from less than $1 \mu \mathrm{m}$ in diameter (1S05) to around $8 \mu \mathrm{m}$ (1S30). On the other hand, the two-step heat-treated samples, where nucleation was promoted, appear textured in their entire volume. This texture, too small to be determined by optical microscopy, causes a drastic loss of transparency as observed in Figure 9, where the UV-Vis spectra of the 7T1G6Ag glass and glass-ceramics obtained are shown. This transmittance reduction is observed in both 
thermal processes. For the one-step sample series, scattering losses seem to be related to the size of the star-like domains, as it coincides with the decrease of transmittance from $71.5 \%$ to $15.2 \%$ at $800 \mathrm{~nm}$ from $1 \mathrm{~S} 05$ to $1 \mathrm{~S} 30$. For the two-step heat-treated samples, the reduction rate is even more drastic. Due to the combination of two heat treatment steps (nucleation and crystal growth), the glass-ceramics become translucent $(2 \mathrm{~S} 15,17.6 \%, 800 \mathrm{~nm})$ and even opaque $(2 \mathrm{~S} 30,<1 \%, 800 \mathrm{~nm})$.

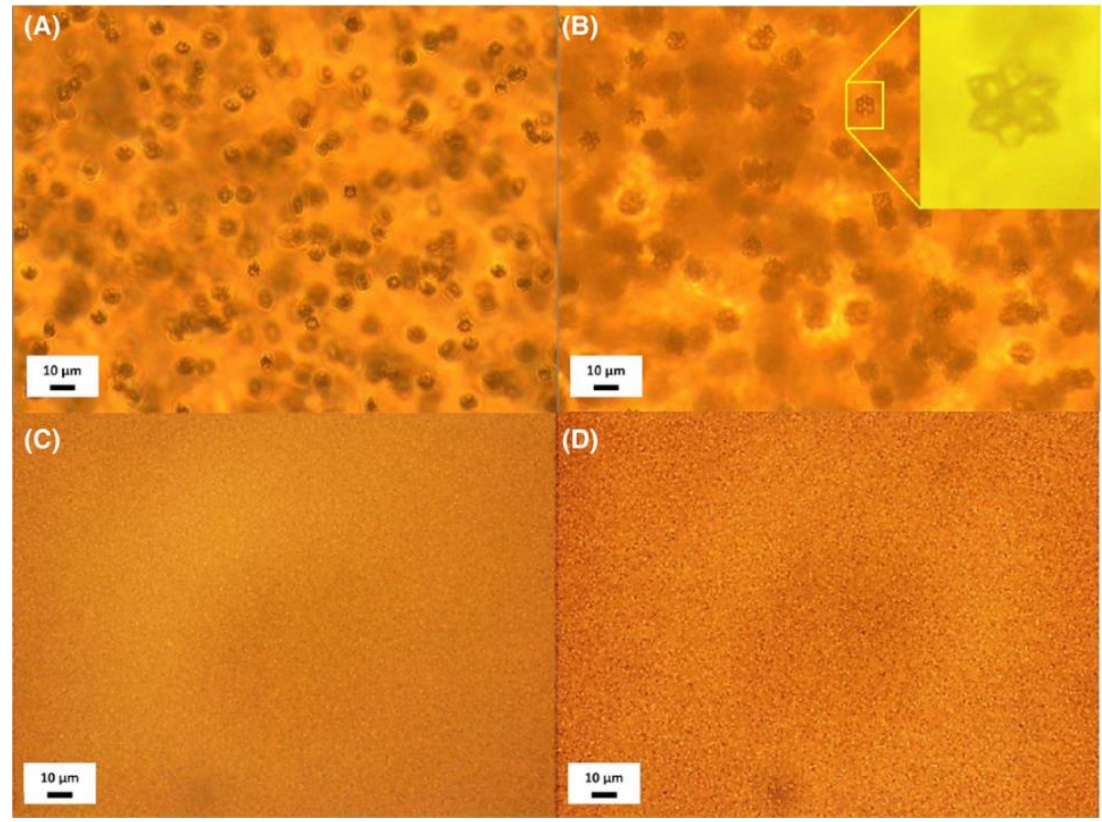

Figure 8. - Optical microscopy images of (A) 1S15, (B) 1S30, (C) 2S15, and (D) 2530 glass-ceramics. The inset illustrates a typical star-like domain from 1530. 

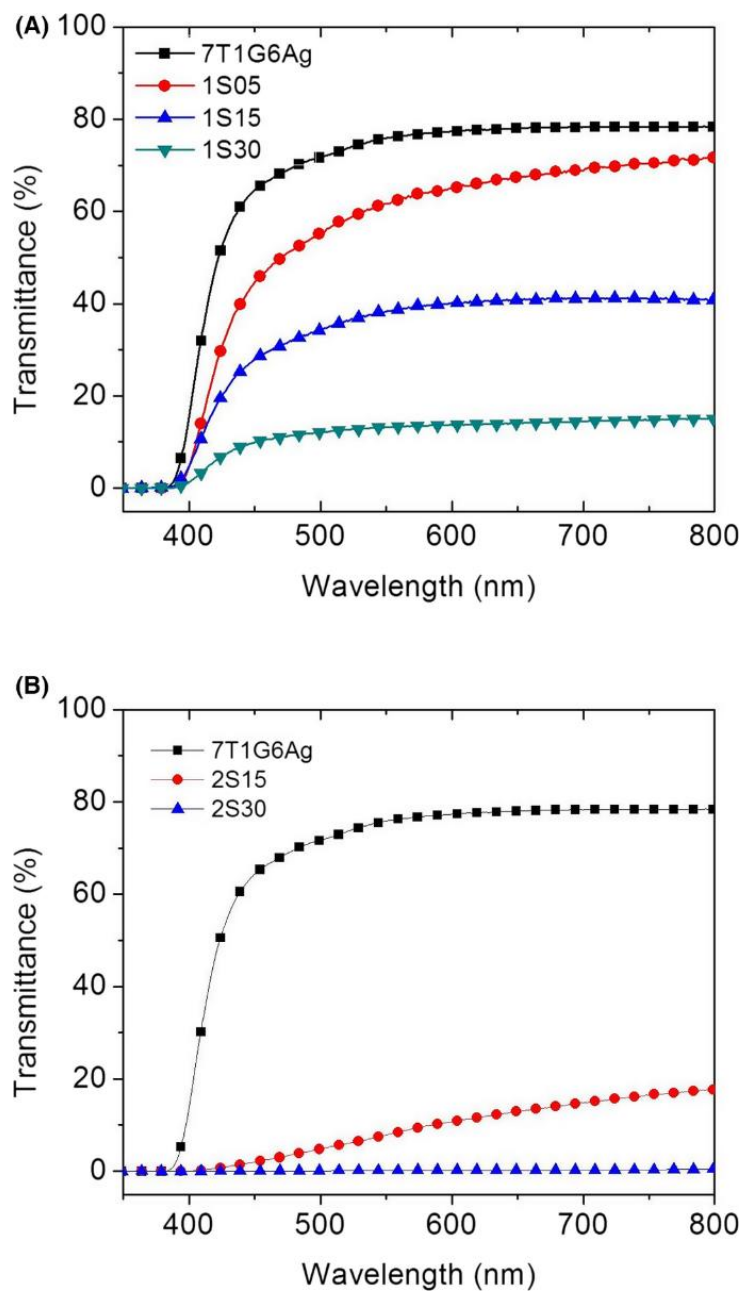

Figure 9. - (A) and (B) are transmittance spectra of glass-ceramics elaborated via one-step and two-step thermal treatments, respectivel.

X-ray diffraction analysis of the $1 \mathrm{~S} 05,1 \mathrm{~S} 15,1 \mathrm{~S} 30,2 \mathrm{~S} 15,2 \mathrm{~S} 30$, and $2 \mathrm{~S} 8 \mathrm{~h}$ samples was performed and the corresponding XRD data are presented in Figure 10. The $2 \mathrm{~S} 8 \mathrm{~h}$ sample shows the presence of a unique crystalline phase with clear XRD pattern that have been assigned to the crystalline phase $\mathrm{K}\left[\mathrm{Nb}_{1 / 3} \mathrm{Te}_{2 / 3}\right]_{2} \mathrm{O}_{4.8}$. [35] The most intense peaks characterizing this crystal phase are observed on the glass-ceramic XRD patterns and increase with the growing treatment durations.

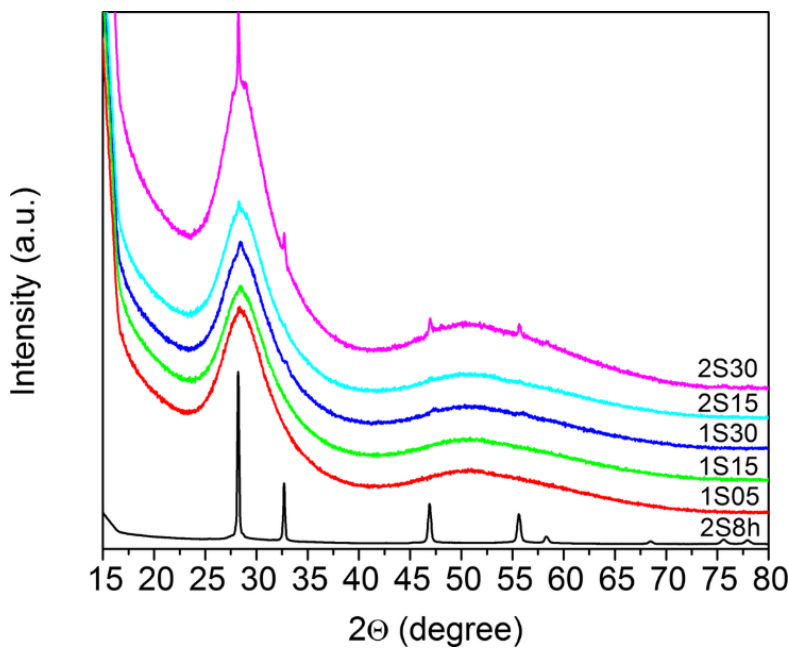

Figure 10. - XRD powder patterns of heat treated samples plus the highly crystallized 2S8 h, for a clear observation of the obtained crystalline phase- $K\left[\mathrm{Nb}_{1 / 3} \mathrm{Te}_{2 / 3}\right]_{2} \mathrm{O}_{4.8}$. 
Macroscopic SHG studies of 1S05, 1S15, 1S30, 2S15, and 2S30 were made and some of them are illustrated in Figure 11. For each sample, polarization scans of the incident beam ( $\Psi$ scan) were performed. One should first notice that the SHG signal is independent to the sample orientation which is in accordance with an isotropic SHG response as previously reported in $\mathrm{LiNbO}_{3}$ and $\mathrm{LaBGeO}_{5}$ glass-ceramics systems. [36] In such system, the global SHG response results from the sum of diluted SHG active center, i.e., individual crystallite or assembly of crystallites. The polarization dependence of the SHG signal informs about the symmetry of the SHG emitters and the global intensity about their concentration or sizes. The SHG $\Psi$ scans, measured on all the 7T1G6Ag glass-ceramics, show a maximum of intensity when the incident polarization correspond to the analyzed SHG polarization (i.e., $\Psi=90^{\circ}$ for $\Psi p$ measurement). Such behavior denotes, in a first approximation, the dipolar nature of the SHG response. The SHG intensity for both 1-step and 2-step samples evolves with heat treatment duration. However, results are quite different, since the 1S- series always show much stronger intensity than the 2S- ones. The SHG intensity of the $1 \mathrm{~S} 30$ sample, for instance, is one order of magnitude higher than the 2S30 sample's. For the two-step heat-treated samples, an increase of the signal is also observed (Figure 11B). This indicates that the nonlinear optical (NLO) signal increases with crystal growth thermal treatment duration.
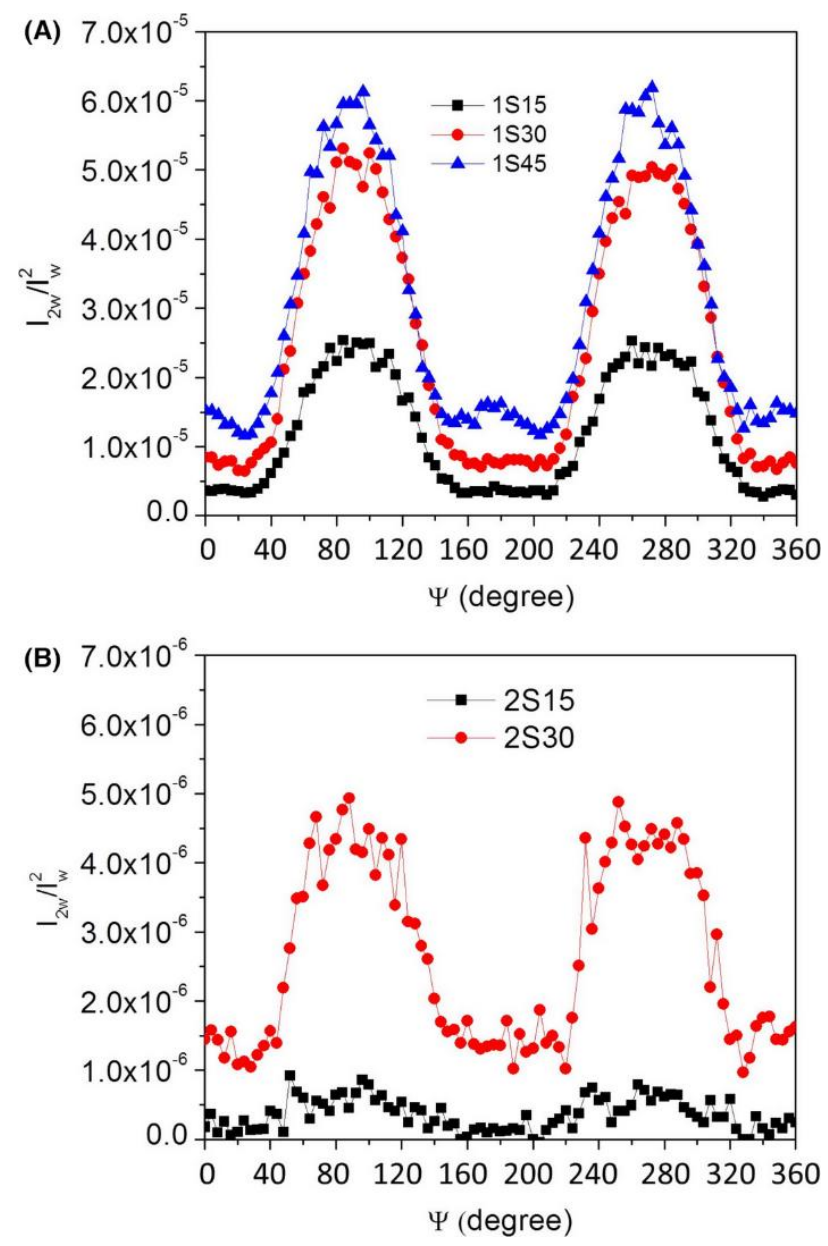

Figure 11. - Macroscopic NLO signal $\left(\Psi_{\mathrm{p}}\right)$ of one-step $(A)$ and two-step (B) treated glass-ceramics materials for different treatment durations. The horizontal axis $(\psi)$ illustrates the polarization angle of electric field.

\section{Discussion}

Heat-treated compositions without silver presented mostly surface crystallization, since after polishing the surfaces a glassy transparent sample was obtained as observed in Figure 2. On the other hand, the silver-doped heat-treated compositions present some loss of transparency as observed in Figure 2 and by the decrease in the UV-Vis transmission 
spectra (Figure 9) even after surface polishing. This indicates that bulk crystallization is promoted with the incorporation of silver. The thermal analysis results have also confirmed the key role of silver, since the onset crystallization of powder DSC scan starts at lower temperature when compared to the bulk sample, indicating that the 7T1G glass crystallizes firstly on the surface. With increasing silver content, a decrease in $T_{\mathrm{g}}$ is observed and the DSC results show a separation of the shoulder present at the lower hand of the crystallization peak, and in fact, for 7T1G4Ag and 7T1G6Ag compositions, we now have two distinct crystallization peaks ( $T_{x 1}$ and $T_{x 2}$ as seen in Figure 3 and described in Table 1). Nevertheless, for the glass composition under study, silver cannot be considered as a classical nucleating agent: first, because of the high concentration needed to observe preferential bulk crystallization ( 6 mol\% of $\mathrm{Ag}_{2} \mathrm{O}$ ) and second, because of its tendency to agglomerate into clusters as deduced from the photoluminescence measurements (Figure 6B). In addition, upon heat treatment around $T_{\mathrm{g}}$, the reduction of silver clusters can lead to the formation of metallic particles. In order to investigate such possibility in our glass system, UV-Vis transmission spectra have been carried out on a 7T1G6Ag glass sample heat treated at the nucleation temperature $\left(340^{\circ} \mathrm{C}\right)$ for different duration (Figure 12$)$. A hump occurs on the transmission curve at $490 \mathrm{~nm}$ for the 30 minute treated sample. This hump decreases significantly for longer treatment times. Such absorption could be assigned to the plasmon band due to the presence of metallic silver nanoparticles. The plasmonic effect of metallic nanoparticles depends on the size and shape of the particles as well as the refractive index of the medium.[37-39] Some studies[40, 41] announced that the plasmonic wavelength for silver particles ranges from 400 to $500 \mathrm{~nm}$, a red shift being expected in high refractive index medium. The observation of a band at $490 \mathrm{~nm}$ in such a high refractive index glass suggests the reduction of silver clusters at the first stages of the nucleation step. The disappearance of the plasmonic hump for longer heat treatment durations might be due to reoxidation and dissolution of the clusters, activated by development of the phase separation and the glass matrix structural rearrangement. Finally, the bulk crystallization achieved seems to involve the coexistence of mechanisms linked to (i) silver ions aggregation/dissolution (ii) phase separation of the glass matrix, and (iii) crystallization within the phase separated domains.

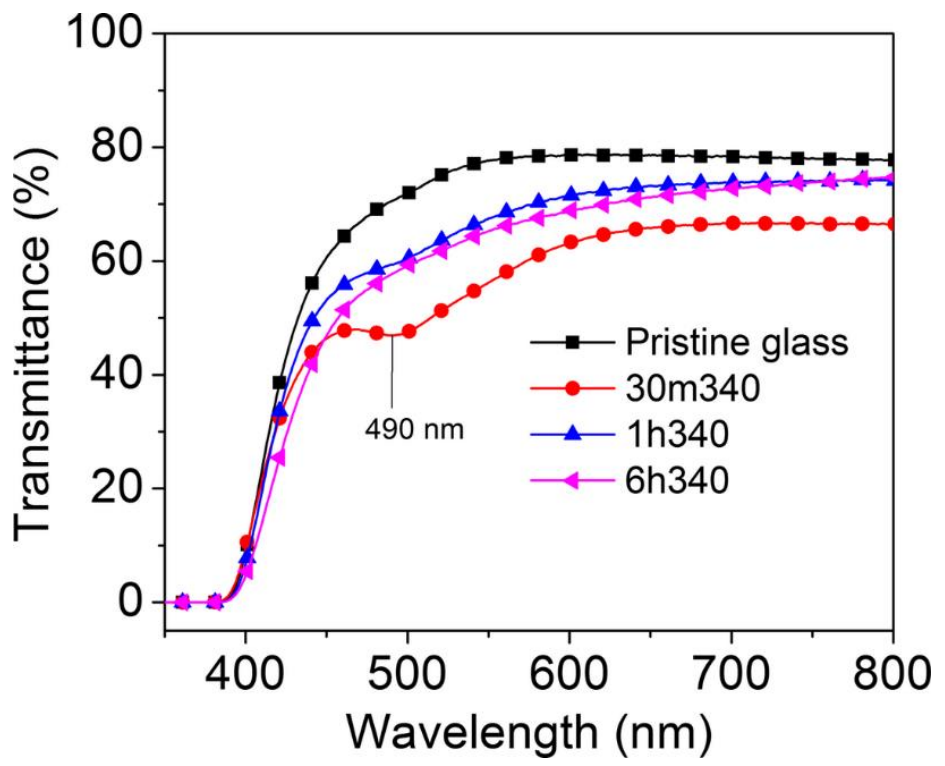

Figure 12. - UV-Vis Transmission spectra of 7T1G6Ag glass heat treated at $340^{\circ} \mathrm{C}$ (nucleation temperature) for different duration.

The key advantage of this kind of glass-ceramics concerns the nonlinear optical properties of the crystalline phase formed at the first stage of the crystallization treatments. One should notice that in heat-treated silver free samples (7T1G glass) the main crystalline phase appearing is $\delta-\mathrm{TeO}_{2}$, which presents no second-order optical properties, since the two crystallization peaks are highly overlapped, making it difficult to obtain the second phase. On the other hand, for 7T1GxAg $(x \neq 0)$, we have two separated crystallization peaks where the crystalline phase $K\left[\mathrm{Nb}_{1 / 3} \mathrm{Te}_{2 / 3}\right]_{2} \mathrm{O}_{4.8}$, a phase showing SHG activity, can be obtained. In fact, it was the unique phase appearing for the 6 mol\% silver-containing glassceramic with a $400^{\circ} \mathrm{C}$ heat treatment (Figure 4). This phase has already been reported in previous studies of tellurite 
glass systems. $[12,42]$ The lattice constant was estimated as $a=5.47 \AA$ and is comparable with previous results in the tellurite glass system.[43] The $\mathrm{K}\left[\mathrm{Nb}_{1 / 3} \mathrm{Te}_{2 / 3}\right]_{2} \mathrm{O}_{4.8}$ crystalline phase is centrosymmetric and is theoretically not SHG active. Nevertheless, it presents NLO activity and some authors[12, 42] proposed that a slight distortion in the structure could be at the origin of the NLO signals, but the explanation on the cause of distortion is still unclear. Kim et al.[42] studied the $15 \mathrm{~K}_{2} \mathrm{O}-15 \mathrm{Nb}_{2} \mathrm{O}_{5}-70 \mathrm{TeO}_{2}$ glass-ceramics and assumed that the structure of the cubic phase is a fluorite-type structure and oxygen vacancies, present in the crystalline phase, could be responsible for the SHG signal. Jeong et al.[44] studied the $x \mathrm{~K}_{2} \mathrm{O}-(14-x) \mathrm{Na}_{2} \mathrm{O}-14 \mathrm{Nb}_{2} \mathrm{O}_{5}-72 \mathrm{TeO}_{2}$ system, where a cubic crystalline phase $\mathrm{Na}\left[\mathrm{Nb}_{1 / 3} \mathrm{Te}_{2 / 3}\right]_{2} \mathrm{O}_{4.8}$

corresponding to $x=0$ was reported to occur but does not present any SHG signal. Hence, the authors suggested that the SHG signal is due to the slight distortion from the fluorite-type structure when $\mathrm{K}^{+}$replaces $\mathrm{Na}^{+}$, due to the higher atomic size of potassium.

Optical images from Figure 8 show several separated domains within the volume. The dependence of the number and size of the domains in the transparency and the optical nonlinearity of glass-ceramics can be deduced from the results depicted in Figures 9 and 11. In fact, the phase separation is already present in the as-quenched glasses and is observed by TEM (Figure 7A,B) as nanometer scale droplets. Some assumptions in the literature in comparable glass systems assigned them to $\mathrm{TeO}_{2}, \mathrm{GeO}_{2}$, and/or $\mathrm{NbO}_{6}$-enriched regions.[14, 45, 46] The presence of phase separation observed by optical microscopy in these glass-ceramics (Figure 8) should be considered to explain the loss of transparency and evolution of SHG signal. Furthermore, although the intensity of the corresponding XRD peaks is observed to increase with the duration of the growth step (Figure 10), it remains small in comparison to the amorphous background revealing a low crystallization rate. Based on the full width at half maximum (FWHM) of the XRD peaks and taking into account the instrumental broadening, the size of crystallites have been estimated by the Scherrer formula to be around 20 and $75 \mathrm{~nm}$ for the $1 \mathrm{~S} 30$ and $2 \mathrm{~S} 30 \mathrm{~h}$ samples, respectively. This result is quite unexpected since Figure 8 clearly shows micron-sized domains. From these results, it follows that the micron sized features are essentially amorphous and could be related to phase separation.

In order to investigate the position of the nanometric crystallites in the glass-ceramic, micro-SHG mapping was performed in the vicinity of a microscopic phase separated domains within the $1 \mathrm{~S} 30$ sample. Figure 13 shows the microSHG map of a star-like domain within the $1 \mathrm{~S} 30$ glass-ceramics ( $8 \mu \mathrm{m}$ in size). The map clearly indicates that the SHG signal is only observed within the star-like domain which indirectly confirmed the size and location of the crystallites.

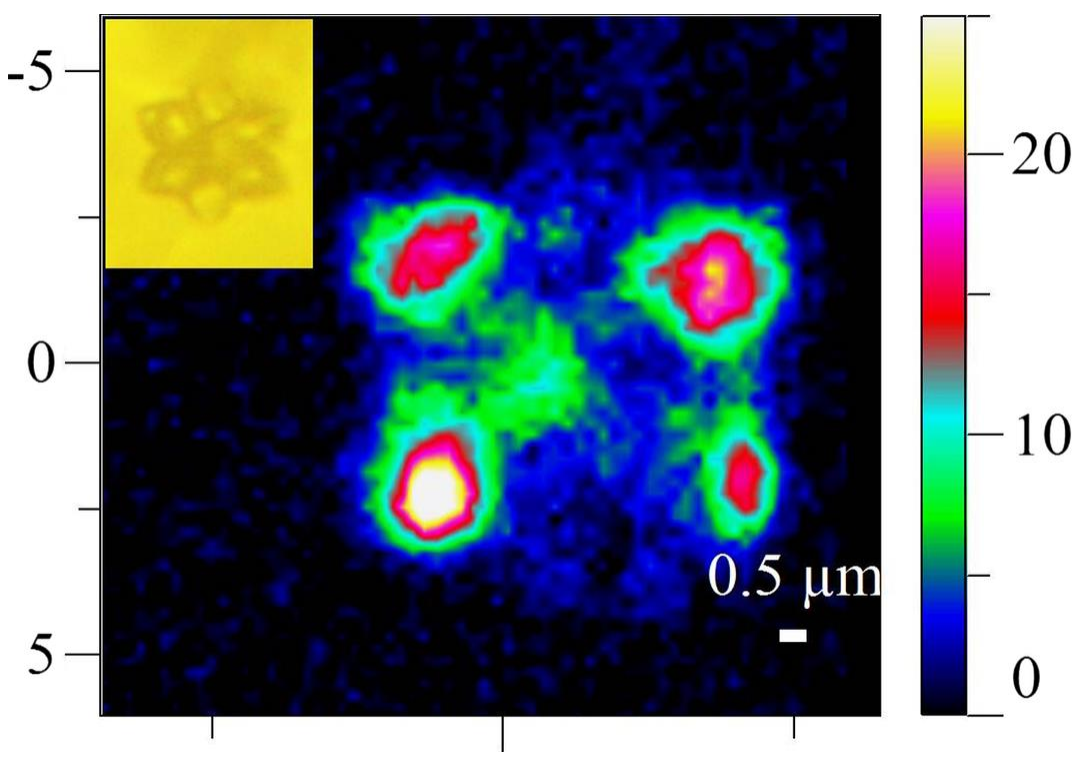

Figure 13. - Microscopic SHG map of a phase separated star-like domain within the 1 S3O glass-ceramic.

To correlate the origin of the SHG signal with the size and distribution of the domains, the $1 S 30$ and the 2 S15 glassceramic materials were chosen for further studies. They both exhibit similar UV-Vis transmission spectra (i.e., comparable transparency as shown in Figure 14A) and similar XRD patterns as depicted in the inset of Figure 14A. 
However, their SHG intensities are drastically different (Figure 14B). The 1 S30 sample shows a signal two-order of magnitude stronger when compared to the $2 \mathrm{~S} 15$ sample. Finally, as transmittance spectra and XRD pattern of these two samples are similar, it is obvious that both the scattering losses and the crystal fraction volume are not at the origin of the large SHG intensity difference observed.
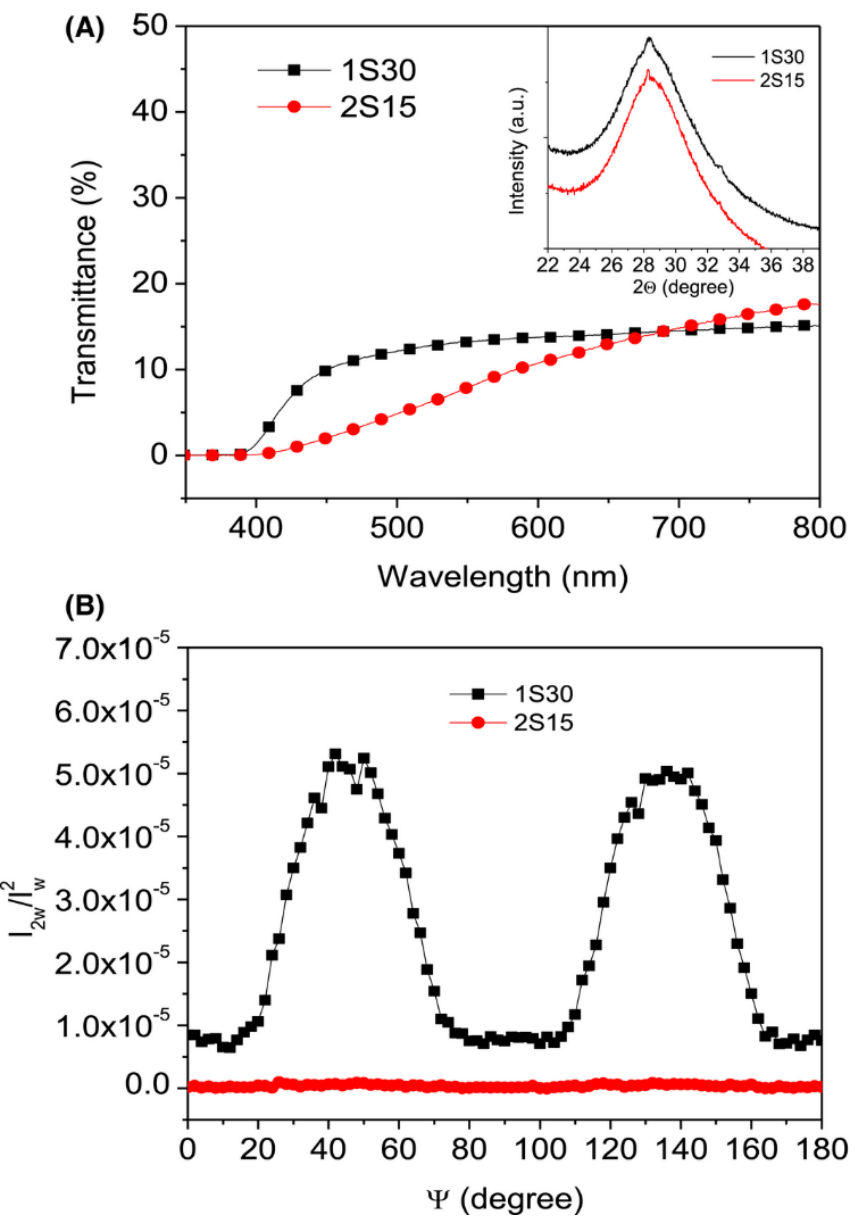

Figure 14. - (A) UV/Vis results for the $1 S 30$ and $2 S 15$ glass-ceramics and respective XRD patterns (inset);(B) $\Psi_{p}$ scans of $1 S 30$ and $2 S 15$ samples. The one-step sample shows a SHG signal two-order of magnitude stronger than the two-step one, even with higher dispersed concentration of phase separation domains.

To explain such difference one should first recall the origin of the SHG signal in such glass-ceramics which results from the sum of diluted SHG active centers. In this case, one SHG-emitter can be considered as a phase separated domain in which SHG-active crystals have grown. From the XRD data, these crystals are in the 20-60 nm range, hence, the high intensity contrast observed between the two samples could originate from: (i) the size of the phase separated domains; and (ii) the crystallite organization inside these domains. The influence of crystallite organization within spherulite type domains was recently study in $\mathrm{LiNbO}_{3}$ silicate and $\mathrm{LaBGeO}_{5}$ germanate glass-ceramics.[6, 36] In these two cases, crystallites have grown with a radial distribution forming the spherulite shape of the crystallized domains. In a first approach, such a radial distribution can be considered as a centrosymmetric arrangement. Nevertheless, strong SHG response was observed in both glass-ceramic systems and attributed to the large size of the spherulite domain (10-30 $\mu \mathrm{m}$ ) as compared to both the wavelength and the coherence length. In this work, the synthesized tellurite glassceramics have shown two distinct cases: (i) the two-step series forming domains with sizes below visible wavelengths and (ii) the one step series with domains sizes up to $15 \mu \mathrm{m}$. Moreover, for the glass-ceramic samples prepared, the main SHG response was found to be of a dipolar nature. Finally, the low SHG response observed for the two-step series glassceramics might be linked to canceling effects due to the local organization of crystallites having a dipolar SHG response in domains with sub-wavelength sizes. Such cancelling effects impose a global centrosymmetric system and thus a low SHG activity. On the other hand, within the star like domains observed for the one-step series samples, one could expect 
a collective organization of the crystallites over distances which could be greater than the wavelength. Thus, a SHG emitter inside the glass-ceramic should be considered as a crystallized volume having a sufficient size and a global noncentrosymmetric organization of the crystallites. As observed by micro-SHG in Figure 13, such collective organization might be observed within each branch of a star-like domain.

\section{Conclusions}

In this study, we have obtained tellurite transparent glass-ceramics with second harmonic generation responses. Addition of silver oxide promotes bulk crystallization and, for the 6 mol\% $\mathrm{Ag}_{2} \mathrm{O}$ composition, the crystalline phase induced by heat treatment in those samples is $\mathrm{K}\left[\mathrm{Nb}_{1 / 3} \mathrm{Te}_{2 / 3}\right]_{2} \mathrm{O}_{4.8}$, which presents second order optical properties.

Although a two-step heat treatment, with a nucleation and a crystal growth step, can improve the nucleation rate, it also enhances phase separation and quickly reduces the transparency of the glass-ceramics. On the other hand, the onestep heat treatment promotes star-like phase separated domains, in which $\mathrm{K}\left[\mathrm{Nb}_{1 / 3} \mathrm{Te}_{2 / 3}\right]_{2} \mathrm{O}_{4.8}$ crystallites nuclei. Furthermore, the SHG intensity is strongly enhanced in the one-step heat treatment. This enhancement is related to the organization of crystallites within the star-like domains.

\section{Acknowledgment}

One of the authors (Lo Nhat Truong) express his gratitude to International Doctoral School in Functional Materials (IDSFunmat), which is one of Erasmus Mundus programs from European Community, who gave the financial support for this work. This work was also supported by the French State, namely by the French National Research Agency (ANR) in the frame of "the Investments for the future" Programme IdEx Bordeaux-LAPHIA (ANR-10-IDEX-03-02). This work was also supported by the Portuguese State, namely the "Fundação para a Ciência e Tecnologia (FCT)", by contract UID/QUI00100/2013. The authors thank the CRMD laboratory for TEM access.

\section{References}

1/ Bloembergen N, Chang R, Jha S, Lee C. Optical second-harmonic generation in reflection from media with inversion symmetry. Phys Rev. 1968;174:813.

2/ Jain H. Transparent ferroelectric glass-ceramics. Ferroelectrics. 2004;306:111-127.

3/ Kaminskii A, Butashin A, Maslyanizin I, et al. Pure and $\mathrm{Nd}^{3+}-\mathrm{Pr}^{3+}$-ion doped trigonal acentric LaBGeO ${ }_{5}$ single crystals nonlinear optical properties, raman scattering, spectroscopy, crystal-field analysis, and simulated emission of their activators. Physica Status Solidi (A). 1991;125:671-696.

4/ Eckardt R, Masuda H, Fan YX, Byer RL. Absolute and relative nonlinear optical coefficients of KDP, $\mathrm{KD}^{*} \mathrm{P}, \mathrm{BaB}_{2} \mathrm{O}_{4}, \mathrm{LilO}_{3}, \mathrm{MgO}$ $\mathrm{LiNbO}_{3}$, and KTP measured by phase-matched second-harmonic generation. IEEE J Quantum Electr. 1990;26:922-933.

5/ Günter P, Asbeck P, Kurtz S. Second-harmonic generation with Ga1-xAlxAs lasers and $\mathrm{KNbO}_{3}$ crystals. Appl Phys Lett. 2008;35:461-463.

6/ Vigouroux H, Fargin E, Gomez S, et al. Synthesis and multiscale evaluation of $\mathrm{LiNbO}_{3}$-containing silicate glass-ceramics with efficient isotropic SHG response. Adv Funct Mater. 2012;22:3985-3993.

7/ Beall G, Duke D. Transparent glass-ceramics. J Mater Sci. 1969;4:340-352.

8/ Chenu S, Véron E, Genevois C, Garcia A, Matzen G, Allix M. Long-lasting luminescent $\mathrm{ZnGa}_{2} \mathrm{O}_{4}$ : $\mathrm{Cr}^{3+}$ transparent glass-ceramics. J Mater Chem C. 2014;2:10002-10010.

9/ Chenu S, Véron E, Genevois C, et al. Tuneable nanostructuring of highly transparent zinc gallogermanate glasses and glassceramics. Adv Opt Mater. 2014;2:364-372.

10/ Kim SH, Yoko T, Sakka S. Linear and nonlinear optical properties of $\mathrm{TeO}_{2}$ glass. J Am Ceram Soc. 1993;76:2486-2490. 
11/ Komatsu T, Honma T. Optical active nano-glass-ceramics. Int J Appl Glass Sci. 2013;4:125-135.

12/ Sakai R, Benino Y, Komatsu T. Enhanced second harmonic generation at surface in transparent nanocrystalline $\mathrm{TeO}_{2}$-based glassceramics. Appl Phys Lett. 2000;77:2118-2120.

13/ Ferreira EA, Cassanjes FC, Poirier G. Crystallization behavior of a barium titanate tellurite glass doped with $\mathrm{Eu}^{3+}$ and $\mathrm{Er}^{3+}$. Opt Mater. 2013;35:1141-1145.

14/ Monteiro G, Santos LF, Pereira J, Almeida RM. Optical and spectroscopic properties of germanotellurite glasses. J Non-Cryst Solids. 2011;357:2695-2701.

15/ Monteiro G, Santos LF, Almeida RM, D'Acapito F. Local structure around $\mathrm{Er}^{3+}$ in $\mathrm{GeO}_{2}-\mathrm{TeO}_{2}-\mathrm{Nb}_{2} \mathrm{O}_{5}-\mathrm{K}_{2} \mathrm{O}$ glasses and glassceramics. J Non-Cryst Solids. 2013;377:129-136.

16/ Smogor H, Cardinal T, Jubera V, et al. Effect of silver on phase separation and crystallization of niobium oxide containing glasses. J Solid State Chem. 2009;182:1351-1358.

17/ Bahadur D, Sudhakar N, Sharma SV, Gupta KP, Majumdar AK. Ag $2 \mathrm{O}$ as nucleating agent in the crystallization of superconducting phase in $\mathrm{Bi}_{2} \mathrm{Sr}_{2} \mathrm{Ca}_{4} \mathrm{Cu}_{5} \mathrm{Y}$ glass composition. Physica C. 1992;190:527-536.

18/ Marotta A, Buri A, Branda F. Nucleation in glass and differential thermal analysis. J Mater Sci. 1981;16:341-344.

19/ Verbiest T, Clays K, Rodriguez V, Second-Order Nonlinear Optical Characterization Techniques: An Introduction. Boca Raton, FL: CRC Press, Frances \& Taylor Group, LLC, 2009.

20/ Udovic M, Thomas $\mathrm{P}$, Mirgorodsky A, et al. Thermal characteristics, Raman spectra and structural properties of new tellurite glasses within the $\mathrm{Bi}_{2} \mathrm{O}_{3}-\mathrm{TiO}_{2}-\mathrm{TeO}_{2}$ system. J Solid State Chem. 2006;179:3252-3259.

21/ Upender G, Babu JC, Mouli VC. Structure, glass transition temperature and spectroscopic properties of $10 \mathrm{Li}_{2} \mathrm{O}-\mathrm{x} \mathrm{P}_{2} \mathrm{O}_{5}-(89-\mathrm{x})$ $\mathrm{TeO}_{2}-1 \mathrm{CuO}(5 \leq x \leq 25$ mol\%) glass system. Spectrochim Acta Part A Mol Biomol Spectrosc. 2012;89:39-45.

22/ Kosuge T, Benino Y, Dimitrov V, Sato R, Komatsu T. Thermal stability and heat capacity changes at the glass transition in $\mathrm{K}_{2} \mathrm{O}-$ $\mathrm{WO}_{3}-\mathrm{TeO}_{2}$ glasses. J Non-Cryst Solids. 1998;242:154-164.

23/ Champarnaud-Mesjard J, Blanchandin S, Thomas P, Mirgorodsky A, Merle-Mejean T, Frit B. Crystal structure, Raman spectrum and lattice dynamics of a new metastable form of tellurium dioxide: $\gamma-\mathrm{TeO}_{2}$. J Phys Chem Solids. 2000;61:1499-1507.

24/ Lin J, Huang W, Sun Z, Ray CS, Day DE. Structure and non-linear optical performance of $\mathrm{TeO}_{2}-\mathrm{Nb}_{2} \mathrm{O}_{5}-\mathrm{ZnO}_{\text {glasses. J Non-Cryst }}$ Solids. 2004;336:189-194.

25/ Chowdari BVR, Pramoda Kumari P. Structure and ionic conduction in the $\mathrm{Ag}_{2} \mathrm{O}-\mathrm{WO}_{3}-\mathrm{TeO}_{2}$ glass system. J Mater Sci. 1998;33:3591-3599.

26/ Rivero C, Stegeman R, Richardson K, et al. Influence of modifier oxides on the structural and optical properties of binary TeO 2 glasses. J Appl Phys. 2007;101:23526-26.

27/ Guery G, Cardinal T, Fargues A, et al. Influence of hydroxyl group on IR transparency of tellurite-based glasses. Int J Appl Glass Sci. 2014;5:178-184.

28/ Wang CY, Shen ZX, Chowdari BVR. Raman studies of $\mathrm{Ag}_{2} \mathrm{O}-\mathrm{WO}_{3}-\mathrm{TeO}_{2}$ ternary glasses. J Raman Spectrosc. 1998;29:819-823.

29/ Amjad RJ, Dousti M, Sahar M. Spectroscopic investigation and Judd-Ofelt analysis of silver nanoparticles embedded Er ${ }^{3+}$-doped tellurite glass. Curr Appl Phys. 2015;15:1-7.

30/ De Araujo CB, Silvério da Silva D, Alves de Assumpção TA, Kassab LRP, Mariano da Silva D, "Enhanced optical properties of germanate and tellurite glasses containing metal or semiconductor nanoparticles," Sci World J, 2013, 385193, 13 pp (2013). 
31/ Paje S, Llopis J, Villegas M, Navarro JF. Photoluminescence of a silver-doped glass. Appl Phys A. 1996;63:431-434.

32/ Eichelbaum M, Rademann K, Hoell A, et al. Photoluminescence of atomic gold and silver particles in soda-lime silicate glasses. Nanotechnology. 2008;19:135701.

33/ Villegas M, Fernández Navarro J, Paje S, Llopis J. Optical spectroscopy of a soda lime glass exchanged with silver. Phys Chem Glasses. 1996;37:248-253.

34/ Bourhis K, Royon A, Papon G, et al. Formation and thermo-assisted stabilization of luminescent silver clusters in photosensitive glasses. Mater Res Bull. 2013;48:1637-1644.

35/ Shioya K, Komatsu T, Kim HG, Sato R, Matusita K. Optical properties of transparent glass-ceramics in $\mathrm{K}_{2} \mathrm{O}-\mathrm{Nb}_{2} \mathrm{O}_{5}-\mathrm{TeO}_{2}$ glasses. J Non-Cryst Solids. 1995;189:16-24.

36/ Truong LN, Dussauze M, Fargin E, et al. Isotropic octupolar second harmonic generation response in $\mathrm{LaBGeO}_{5}$ glass-ceramic with spherulitic precipitation. Appl Phys Lett. 2015;106:161901.

37/ Rai VN, Srivastava AK, Mukherjee C, Deb SK, Localized surface plasmon resonance (LSPR) and refractive index sensitivity of vacuum evaporated nanostructured gold thin films. arXiv preprint arXiv:1406.4605; 2014.

38/ Mock J, Barbic M, Smith D, Schultz D, Schultz S. Shape effects in plasmon resonance of individual colloidal silver nanoparticles. J Chem Phys. 2002;116:6755-6759.

39/ Lee K-S, El-Sayed MA. Gold and silver nanoparticles in sensing and imaging: sensitivity of plasmon response to size, shape, and metal composition. J Phys Chem B. 2006;110:19220-19225.

40/ Mock JJ, Smith DR, Schultz S. Local refractive index dependence of plasmon resonance spectra from individual nanoparticles. Nano Lett. 2003;3:485-491.

41/ González A, Noguez C, Beránek J, Barnard A. Size, shape, stability, and color of plasmonic silver nanoparticles. J Phys Chem C. 2014;118:9128-9136.

42/ Kim HG, Komatsu T, Shioya K, Matusita K, Tanaka K, Hirao K. Transparent tellurite-based glass-ceramics with second harmonic generation. J Non-Cryst Solids. 1996;208:303-307.

43/ Jeong E, Bae J, Hong T, et al. Thermal properties and crystallization kinetics of tellurium oxide based glasses. J Ceram Proc Res. 2007;8:417.

44/ Jeong ED, Borse PH, Lee JS, et al. Second harmonic generation and fabrication of transparent $\mathrm{K}_{2} \mathrm{O}-\mathrm{Na}_{2} \mathrm{O}-\mathrm{Nb}_{2} \mathrm{O}_{5}-\mathrm{TeO}_{2}$ glassceramics. J Ind Eng Chem. 2006;12:790-794.

45/ Kim H, Komatsu T. Fabrication and properties of transparent glass-ceramics in $\mathrm{Na}_{2} \mathrm{O}-\mathrm{Nb}_{2} \mathrm{O}_{5}-\mathrm{TeO}_{2}$ system. J Mater Sci Lett. 1998;17:1149.

46/ Dimitriev $\mathrm{Y}$, Kashchieva $\mathrm{E}$, Koleva $\mathrm{M}$. Phase separation in tellurite glass-forming systems containing $\mathrm{B}_{2} \mathrm{O}_{3}, \mathrm{GeO}_{2}, \mathrm{Fe}_{2} \mathrm{O}_{3}, \mathrm{MnO}$, CoO, NiO and CdO. J Mater Sci. 1981;16:3045-3051. 